Jo Swartz MD FRCPC.

Bernard M. Braude MB BCh DA(SA) FFA(SA) FRCPC,

Robert F. Gilmour MASc PEng.

Barry Shandling MB BCh FRCS FACS FRCSC,

Milton Gold MD FRCPC

\section{Intraoperative anaphylaxis to latex}

This case report describes intraoperative anaphylaxis occurring in a fourteen-year-old female with spina bifida in which latex surgical gloves were incriminated as the aetiologic agent. The patient was non-atopic but since eight years of age she had developed localized angioedema and urticarial skin reactions on exposure to rubber. She had previously undergone several uneventful surgical procedures. Forty-five minutes following induction of anaesthesia and during laparotomy for elective cholecystectomy she experienced sudden onset of increased airway pressure, oxygen desaturation, tachycardia, profound hypotension and erythema consistent with an anaphylactic reaction. Resuscitation with manual ventilation and oxygen, intravenous fluids and an epinephrine infusion was successful. Subsequent investigations for allergies demonstrated a strongly positive skin prick test and RAST to latex antigen, with negative results to anaesthetic agents, antibiotics and inhalant allergens. During two later operations prophylaxis consisting of diphenhydramine, ranitidine and hydrocortisone appeared to prevent further reactions. Latex should be considered as a cause of life-threatening intraoperative allergic reactions in patients with a history of rubber allergy or frequent exposure to latex products.

Le latex des gants du chirurgien semble responsable de l'anaphylaxie intra-opératoire survenue chez une fille de quatorze ans atteinte de spina-bifida. La patiente, sans autre histoire $d$ atopie, manifestait depuis l'àge de huit ans un urticaire avec angioedème local lors de contacts avec du caoutchouc mais elle avait subi sans problème, diverses interventions chirurgicales. Approximativement 45 minutes après l'induction de l'anesthésie

\section{Key words}

ALLERGY: anaphylaxis, latex; COMPLICATIONS: anaphylaxis.

From the Department of Anaesthesia, Division of Allergy, Department of Paediatrics, Department of Paediatric Surgery, and the Department of Medical Engineering, The Hospital for Sick Children, Toronto, Ontario, Canada M5G IX8.

Address correspondence to: Dr. J. Swartz, Department of Anaesthesia, AE203, Harry Medovy House, Children's Hospital, 840 Sherbrook Street, Winnipeg, Manitoba, Canada R3C 1S1. pendant une laparotomie pour cholecystectomie, il y eut chez elle une augmentation soudaine de la pression des voies respiratoires avec désaturation artérielle, hypotension grave et un érythème, le tout compatible avec un choc anaphylactique. La réanimation consista en une ventilation manuelle l'oxygène, du liquide par voie intraveineuse et une perfusion d' adrénaline. Une cuti-réaction et un test de radioallergosorbent (RAST) s'avérèrent fortement positifs pour l'antigène du latex-'alors que la réponse aux anesthésiques, antibiotiques et autres allergènes en inhalation était négative. Lors de deux interventions subsé. quentes, une prophylaxie base de diphenhydramine, de ranitidine et d'hydrocortisone fut utilisée avec succès. On devrait considérer le latex comme un agent pouvant potentiellement déclencher une réaction allergique intra-opératoire sérieuse chez ceux qui sont fréquemment en contact avec lui ou qui sont allergiques au caoutchouc.

Anaphylactic reactions which occur intraoperatively are usually attributed to drug administration. However, recent reports suggest that tissue contact with both medical and non-medical latex products such as rubber catheters, gloves or toy balloons may precipitate immunoglobulin $\mathrm{E}$ (IgE)-mediated anaphylactic reactions. ${ }^{1-3}$

We report a case in which latex surgical gloves were suspected as the cause of intraoperative anaphylaxis. We discuss our treatment of the acute event, the investigation of this condition and finally the management of this patient during two subsequent surgical procedures.

\section{Case report}

A 14-year-old female weighing $44 \mathrm{~kg}$ with a history of biliary colic was admitted for cholecystectomy. She had spina bifida with paraparesis and a neurogenic bowel and bladder. Her medications at the time of admission included ephedrine and probanthine for bladder dysfunction. The patient had required bladder catheterization from birth, at times with rubber catheters. At eight years of age she had developed periorbital oedema, erythema and lip-tingling after blowing up toy balloons, and papular lesions on her hands following contact with rubber gloves. Exposure to rubber balloons and gloves was thereafter avoided. She had no other known allergies and the remainder of the functional inquiry was negative. She had undergone eight previous uneventful surgical 
procedures under general anaesthesia including meningomyelocoele repair and ventriculoperitoneal (VP) shunt insertion at birth and later, Luque rod instrumentation, cystoscopy and tendon releases.

Before surgery, ampicillin and gentamicin were given intravenously. In the operating room, following placement of routine monitors, assessment of vital signs, and preoxygenation, anaesthesia was induced intravenously with thiopentone $200 \mathrm{mg}$ and succinylcholine $60 \mathrm{mg}$. The trachea was easily intubated with a $7.0 \mathrm{~mm}$ cuffed tracheal tube and, following confirmation of clear air entry bilaterally, the lungs were ventilated with an Air Shields ventilator at a rate of 14 breaths per minute, with peak airway pressures (Paw) of $20 \mathrm{cmH}_{2} \mathrm{O}$ and a tidal volume of $500 \mathrm{ml}$. Post-intubation vital signs were stable including heart rate (110 beats per minute), blood pressure (120 mmHg systolic), $\mathrm{O}_{2}$ saturation (98 per cent), $\mathrm{PeTCO}_{2}(35 \mathrm{mmHg})$ and axillary temperature $\left(36.4^{\circ} \mathrm{C}\right)$. Fentanyl $40 \mu \mathrm{g}$ and vecuronium $4.0 \mathrm{mg}$ were given intravenously and isoflurane 1.5 per cent in $\mathrm{N}_{2} \mathrm{O} / \mathrm{O}_{2}$ $\left(\mathrm{FIO}_{2} 0.4\right)$ was added into the circle circuit.

Forty-five minutes following induction of anaesthesia, and soon after intra-abdominal manipulation had begun and packs inserted, the patient suddenly developed increased Paw $\left(40 \mathrm{cmH}_{2} \mathrm{O}\right)$ and decreased $\mathrm{O}_{2}$ saturation ( 88 per cent). This was rapidly followed by profound hypotension (40-50 mm systolic) and a sinus tachycardia of 140 beats per minute. Surgery was immediately halted and the abdominal packs removed with no detectable improvement in vital signs. Air entry was noted to be severely diminished bilaterally with almost complete absence of breath sounds and a persistently elevated Paw. The patient was given 100 per cent oxygen and the lungs were ventilated manually with difficulty. Isoflurane was discontinued as the patient remained hypotensive. An intraoperative chest $x$-ray was interpreted as normal. Generalized erythema, not obvious earlier, was first noted during the 45-minute period of resuscitation. She required several bolus doses of epinephrine $\left(1-5 \mu \mathrm{g} \cdot \mathrm{kg}^{-1}\right)$ and vital signs were finally stabilized with a continuous infusion of epinephrine $\left(0.25 \mu \mathrm{g} \cdot \mathrm{kg}^{-1} \cdot \mathrm{min}^{-1}\right)$. At this time blood pressure was $120 / 70$, heart rate was 120 beats per minute and air entry had improved bilaterally with a reduction in Paw to $25 \mathrm{cmH}_{2} 0$. She also received $2.5 \mathrm{~L}$ of lactated Ringer's solution, $500 \mathrm{ml}$ of 5 per cent albumin, and methylprednisolone $1 \mathrm{~g}$ and diphenhydramine $50 \mathrm{mg}$ intravenously. As it was deemed necessary to proceed at least with a cholecystostomy, anaesthesia was continued with fentanyl, vecuronium and isoflurane 0.5 per cent in $\mathrm{N}_{2} \mathrm{O} / \mathrm{O}_{2}\left(\mathrm{FIO}_{2} \quad 0.5\right)$ and the epinephrine infusion was maintained. Following surgery, the patient was transferred to the intensive care unit where the lungs were ventilated overnight and the trachea extubated the next morning at which time vital signs were stable and she was alert. She was discharged from hospital five days after surgery.

Blood for complete blood count (CBC) and total $\lg E$ was taken at the time of the reaction. Results of the CBC were not remarkable. In particular the eosinophil count both intraoperatively ( 0.46 per cent) and at 72 hours postoperatively $(0.30$ per cent) was within the normal range for our hospital $(<0.5$ per cent). Total $\operatorname{lgE}$ measured $600 \mu \mathrm{g} \cdot \mathrm{L}^{-1}$, the normal value in our hospital being $<98 \mu \mathrm{g} \cdot \mathrm{L}^{-1}$.

Two months following cholecystostomy the patient underwent allergy testing. Skin prick tests (SPT) ${ }^{4}$ and intradermal skin test $\mathrm{s}^{5}$ were performed to anaesthetic agents (fentanyl, succinylcholine, thiopentone, vecuronium), and penicillin. Inhalant allergens (animal dander, dust, grasses, molds, pollens, trees) and latex were tested by SPT alone. Only latex antigen resulted in a positive skin test with a $10 \times 15 \mathrm{~mm}$ wheal and $30 \mathrm{~mm}$ of erythema. Ten non-atopic individuals served as controls for the latex SPT, and their results were negative. Blood was also obtained for a radioallergosorbent (RAST) test. ${ }^{6}$ The RAST test to latex was positive with 28.4 per cent binding compared to the control binding of 2.3 per cent. Our patient's reaction was thus most likely secondary to tissue contact with the latex surgical gloves used during laparotomy.

At this time the patient developed a decubitus ulcer which required two operations. She was asymptomatic with regard to her biliary tract disease and was otherwise well. In preparation for these operations the patient received IV premedication with hydrocortisone $5 \mathrm{mg} \cdot \mathrm{kg}^{-1}$ $\mathrm{q} 6 \mathrm{~h} \times 3$ doses, diphenhydramine $1 \mathrm{mg} \cdot \mathrm{kg}^{-1} \mathrm{q} 6 \mathrm{~h} \times 3$ doses, and ranitidine $2 \mathrm{mg} \cdot \mathrm{kg}^{-1} \mathrm{q} 12 \mathrm{~h} \times 2$ doses, the final dose of each drug being given in the hour prior to surgery. In the operating room following routine monitor placement anaesthesia was induced with diazepam $0.2 \mathrm{mg}$. $\mathrm{kg}^{-1}$, ketamine $2 \mathrm{mg} \cdot \mathrm{kg}^{-1}$, fentanyl $2.5 \mu \mathrm{g} \cdot \mathrm{kg}^{-1}$ and maintained with $\mathrm{N}_{2} \mathrm{O} / \mathrm{O}_{2}\left(\mathrm{FlO}_{2} 0.3\right)$ by face mask and a ketamine infusion of $4-7 \mathrm{mg} \cdot \mathrm{kg}^{-1} \cdot \mathrm{hr}^{-1}$. Each procedure lasted approximately 3.5 hours and was uneventful.

A urinary catheter was not used during either the cholecystostomy or the two subsequent plastic surgical procedures. However, latex surgical gloves were used during the two subsequent operations, and other latex products were not specifically avoided.

\section{Discussion}

The incidence of anaphylaxis during anaesthesia has increased over the past 15 to 20 years and is now approximately $1 / 1500-1 / 5000 .{ }^{4}$ The estimated mortality is $1 / 40,000 .{ }^{4}$ The reason for this apparent increase may be related to better recognition and reporting, or alternatively 
to the use of multiple medications and possible crosssensitivity between drugs. Anaesthetic agents, antibiotics, blood products, colloid volume expanders and radiocontrast dyes have often been incriminated in these anaphylactic reactions.

Our patient developed sudden severe cardiorespiratory compromise 45 min after routine induction of anaesthesia, but within minutes of contact between exposed tissues and rubber gloves. As a diagnosis of anaphylaxis was not certain during the early period of resuscitation other causes of cardiorespiratory failure including endotracheal tube occlusion, obstruction or malposition, circuit malfunction or disconnections, aspiration pneumothorax, pulmonary embolism, incorrect drug administration, and vena caval obstruction were considered and excluded. The diagnosis of anaphylaxis was based on the presence of increased $\mathrm{Paw}$, decreased $\mathrm{O}_{2}$ saturation, severe hypotension and diffuse erythema. Although there was no temporal relationship between the allergic reaction and drug administration, we initially considered a drugrelated aetiology. However, in the light of past experience at our hospital, ${ }^{7}$ and her history of allergy to rubber, latex was also considered as a possible cause of this patient's sudden intraoperative collapse. We postulated that this patient may have become sensitized to latex following absorption of the latex antigen through microscopic tears in the urethral or rectal mucosa induced by repeated manipulations and as a result of multiple surgical procedures using latex surgical gloves. This explanation could account for her reaction to rubber balloons. Previous operative procedures may then have enhanced the sensitization process which culminated in an intraoperative anaphylactic reaction precipitated by tissue contact with latex surgical gloves. The single elevated $\mathrm{IgE}$ level may indicate a specific IgE antibody to latex in this non-atopic patient. This discordance is seen with allergic reactions to other antigens such as anaesthetic agents, ${ }^{8}$ penicillin reagents, ${ }^{9}$ and bee stings. ${ }^{10}$ As skin testing to all other agents was negative, the positive SPT and highly positive RAST to latex incriminated this material as the most likely aetiological factor.

Latex, a previously unrecognized protein allergen, has now been reported to cause anaphylaxis via an IgEmediated mechanism. ${ }^{1-3,11-13}$ Latex is a milky sap obtained from the rubber tree (Hevea brasiliensis). This natural product is combined with low molecular weight agents such as antioxidants, accelerators and other chemical additives to form synthetic rubber with increased durability, elasticity and strength. ${ }^{14}$ Contact dermatitis, a result of sensitization to these chemical additives, was once thought to be the only type of allergic response to rubber. ${ }^{14}$ However, there are recent reports of IgEmediated reactions attributed specifically to latex and not to chemical additives. These reactions have manifested as urticaria, $^{15}$ rhinitis, $^{16}$ asthma, $^{17}$ angioedema $^{6.7}$ and anaphylaxis. ${ }^{1-3,11-13}$

Several investigators believe that the incidence of allergic reactions to latex is underestimated and that episodes may go unrecognized. ${ }^{2,12}$ A history of reaction to latex products such as rubber balloons, catheters, gloves and dental cofferdams is very suggestive. Patients who may be at increased risk are those with disorders which require repeated exposure to latex products. Leynadier and colleagues ${ }^{2}$ reported a series of five patients with documented urticaria following repeated contact with latex gloves. Four of these patients developed anaphylaxis during surgery, two during general anaesthesia and two during spinal anaesthesia. The fifth patient developed anaphylaxis before induction of anaesthesia after a urethral latex probe was inserted by a nurse wearing latex gloves. Skin prick, RAST and human basophil degranulation tests to latex were positive in all five patients. Slater ${ }^{1}$ described two non-atopic 11 -year-old females with spina bifida. One child had urticaria and rhinorrhea and the other angioedema on exposure to rubber balloons. Both children developed intraoperative anaphylaxis, the first during orthopaedic surgery, the second during VP shunt revision. SPTs and human basophil degranulation tests to latex were positive in both patients. Anaesthetic agents were excluded as the cause of anaphylaxis in all the above cases. Two similar patients were described by Gerber, ${ }^{3}$ one with spina bifida and the other with oesophageal atresia. It is essential therefore that preoperative histories in such patients include information about possible sensitivities and/or a history of repeated exposure to rubber materials. Skin prick testing and/or RAST testing to latex may assist in the preoperative evaluation of these patients.

Preventive measures involve avoidance of known precipitating agents and the use of prophylactic medications. If possible, latex gloves should be avoided. Acceptable substitutes would be those made of vinyl (e.g., Tru-Touch ${ }^{\circledR}$ ) or other non-latex gloves such as Elastyren $^{\otimes}$, Neolon ${ }^{\otimes}$ and Dispos-a-glove ${ }^{\circledR}{ }^{13}$ Urinary catheters made of silastic or polyvinylchloride should replace rubber catheters in the management of these patients. A prophylactic drug regimen that can prevent anaphylactic reactions with absolute certainty has not been described. Recent use of combinations of $\mathrm{H}_{1}$ and $\mathrm{H}_{2}$ blocking agents with steroids has been recommended and found to be effective in the prevention of serious radiographic contrast material reactions. ${ }^{18}$ Similar measures were used without complication for this patient during her two subsequent operations. The management and investigation of allergic drug reactions during anaesthesia have recently been reviewed. ${ }^{19,20}$ 
This case report underlines the need to investigate the role of materials as well as drugs in the aetiology of anaphylaxis. Latex is a newly recognized allergen. Our experience with this patient demonstrates that allergic reactions to latex may have life-threatening consequences.

\section{Acknowledgements}

We thank Dr. R. E. Creighton for piquing our curiosity and his encouragement, Dr. J. Dolovich for performing the RAST test and Ms. T. Cain and Ms. J. Thom for their assistance in the preparation of this manuscript.

\section{References}

I. Slater JE. Rubber anaphylaxis. N Engl J Med 1989; 320: 1126-30.

2 Leynadier F, Pecquet $C$, Dry J. Anaphylaxis to latex during surgery. Anaesthesia 1989; 44: 547-50.

3 Gerber AC, Jorg W, Zbinden S, Seger RA, Dangel $P H$. Severe intraoperative anaphylaxis to surgical gloves: latex allergy, an unfamiliar condition. Anesthesiology 1989; 71: 800-02.

4 Leynadier $F$, Sansarricq $M$, Didier $J M$, Dry J. Prick tests in the diagnosis of anaphylaxis to general anaesthetics. Br J Anaesth 1987; 59: 683-9.

5 Fisher $M$. Intradermal testing after anaphylactoid reaction to anaesthetic drugs: practical aspects of performance and interpretation. Anaesth Intensive Care 1984; 12: 115-20.

6 Gleich $G H$, Yunginger $J W$. The radioallergosorbent test: a method to mcasure IgE antibodics, IgG blocking antibodies and the potency of allergy extracts. Bull NY Acad Mcd 1981; 57: 559-67.

7 Lozynsky OA, Dupuis L, Shandling B, Gilmour RF, Zimmerman $B$. Anaphylactoid and systemic reactions following saline enema administration. Six case reports. Ann Allergy 1986; 56: 62-6.

8 Fisher $M M C D$, Outhred A, Bowey CJ. Can clinical anaphylaxis to anaesthetic drugs be predicted from allergic history? Br J Anaesth 1987; 59: 690-2.

9 Green GR, Rosenblum A. Report of the penicillin study group: American Academy of Allergy. J Allergy Clin Immunol 1971; 48: 331-43.

10 Reisman RE. Insect Allergy. In: Allergy: Principles and Practice. Middleton E Jr (Ed.). 3rd ed. St.Louis: The C.V. Mosby Company, 1988: 1345-64.

11 Axelsson JGK, Johansson SGO, Wrangsjo K. IgE-mediated anaphylactoid reactions to rubber. Allergy 1987; 42: 46-50.
12 Axelsson $I G K$, Eriksson $M$, Wrangsjo $K$. Anaphylaxis and angioedema due to rubber allergy in children. Acta Paediatr Scand 1988; 77: 314-6.

13 Spaner D, Dolovich J, Tarlo S, Sussman G, Buttoo $K$. Hypersensitivity to natural latex. J Allergy Clin Immunol 1989; 83: 1135-7.

14 Taylor JS. Rubber. In: Contact Dermatitis. Fisher AA (Ed.). Philadelphia: Lea \& Febiger: 1986, 603-43.

15 Nutter $A F$. Contact urticaria to rubber. Br J Dermatol 1979; 101: 597-8.

16 Carrillo T, Cuevas M, Munoz T, Hinojosa M, Moneo I. Contact urticaria and rhinitis from latex surgical gloves. Contact Dermatitis 1986; 15: 69-72.

17 Seaton A, Cherrie B, Turnbull J. Rubber glove asthma. Br Med J 1988; 296: 531-2.

18 Myers $G E$, Bloom $F L$. Cimetidine combined with steroids and $\mathrm{H}_{1}$ antihistamines for the prevention of serious radiographic contrast material reactions. Cathet Cardiovasc Diag 198I; 7: 65-9.

19 Watkins $J$. Investigation of allergic and hypersensitivity reactions to anaesthetic agents. Br J Anaesth 1987; 59: 104- 11.

20 Moudgil GC. Anaesthesia and allergic drug reactions. Can Anaesth Soc J 1986; 33: 400-14. 